\title{
K. Masumori, K. Maeda, Y. Koide, T. Hanai, H. Sato, H. Matsuoka, H. Katsuno, T. Noro, K. Honda, T. Endo, S. Shiota and S. Matsuoka: Simple excision and closure of a distal limb of loop colostomy prolapse by stapler device
}

\author{
F. La Torre
}

Received: 6 October 2011/Accepted: 7 October 2011/Published online: 3 November 2011

(c) Springer-Verlag 2011

The authors propose a new simple surgical technique for treating prolapse of the efferent loop after transverse loop colostomy. This new surgical technique has been used only in 2 patients, including one who underwent colostomy closure within a year. I would not recommend it for longterm treatment of prolapsed stoma because it does not treat the most important underlying cause of efferent loop prolapse which is the lack of internal fixation. Stomal prolapse interferes with patient's quality of life and may cause occlusive symptoms, severe dermatitis and bleeding, therefore requiring surgical correction. Several minimally invasive options have been described for short-term treatment of stomal prolapse [1,2]. These are valid options only if stoma closure is planned. Otherwise, given the $25 \%$ recurrence rate after simple resection [3, 4], fixation of the efferent loop and/or conversion to an end colostomy is still the gold standard for treating this complication $[5,6]$.

Conflict of interest The author has declared that no conflict of interest exists.

\section{References}

1. Maeda K, Maruta M, Utsumi T et al (2004) Local correction of a transverse loop colostomy prolapse by means of a stapler device. Tech Coloproctol 8:45-46

2. Seamon LG, Richardson DL, Pierce M, O’Malley DM, Griffin S, Cohn DE (2008) Local correction of extreme stomal prolapse following transverse loop colostomy. Gynecol Oncol 111:549-551

3. Salvadalena G (2008) Incidence of complications of the stoma and peristomal skin among individuals with colostomy, ileostomy, and urostomy: a systematic review. J Wound Ostomy Continence Nurs 35:596-607

4. Mäkelä JT, Turku PH, Laitinen ST (1997) Analysis of late stomal complications following ostomy surgery. Ann Chir Gynaecol $86: 305-310$

5. Edwards DP, Leppington-Clarke A, Sexton R, Heald RJ, Moran BJ (2001) Stoma-related complications are more frequent after transverse colostomy than loop ileostomy: a prospective randomized clinical trial. Br J Surg 88:360-363

6. Leenen LP, Kuypers JH (1989) Some factors influencing the outcome of stoma surgery. Dis Colon Rectum 32:500-504

F. La Torre $(\bowtie)$

Department of Emergency, Colorectal and Pelvic Surgery

Unit - Policlinico Umberto 1, Sapienza University Hospital,

Rome, Italy

e-mail: filippo.latorre@uniromal.it 